\title{
Summary Report: INL CDCIS Cask Scanner Testing at Doel, Belgium
}

C. Jayson Wharton, Edward H.Seabury, A.J. Caffrey, and Philip L. Winston April 2013

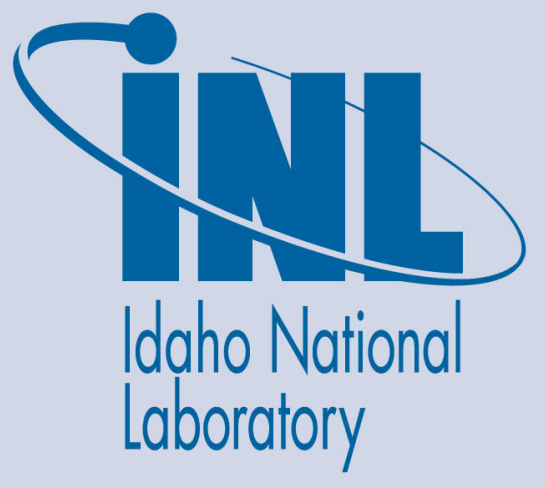

The INL is a U.S. Department of Energy National Laboratory operated by Battelle Energy Alliance 


\section{DISCLAIMER}

This information was prepared as an account of work sponsored by an agency of the U.S. Government. Neither the U.S. Government nor any agency thereof, nor any of their employees, makes any warranty, expressed or implied, or assumes any legal liability or responsibility for the accuracy, completeness, or usefulness, of any information, apparatus, product, or process disclosed, or represents that its use would not infringe privately owned rights. References herein to any specific commercial product, process, or service by trade name, trade mark, manufacturer, or otherwise, does not necessarily constitute or imply its endorsement, recommendation, or favoring by the U.S. Government or any agency thereof. The views and opinions of authors expressed herein do not necessarily state or reflect those of the U.S. Government or any agency thereof. 


\title{
Summary Report: INL CDCIS Cask Scanner Testing at Doel, Belgium
}

\author{
C. Jayson Wharton, Edward H. Seabury, A.J. Caffrey, and Philip L. Winston
}

April 2013

Idaho National Laboratory Non-Proliferation Programs

Idaho Falls, Idaho 83415

http://www.inl.gov

Prepared for the

U.S. Department of Energy

Office of National Nuclear Security Administration

Under DOE Idaho Operations Office

Contract DE-AC07-05ID14517 



\title{
Non-Proliferation Programs
}

\section{Summary Report: INL CDCIS Cask Scanner Testing at Doel, Belgium}

\author{
INL/EXT-13-28809 \\ Revision 0
}

April 2013

Approved by:
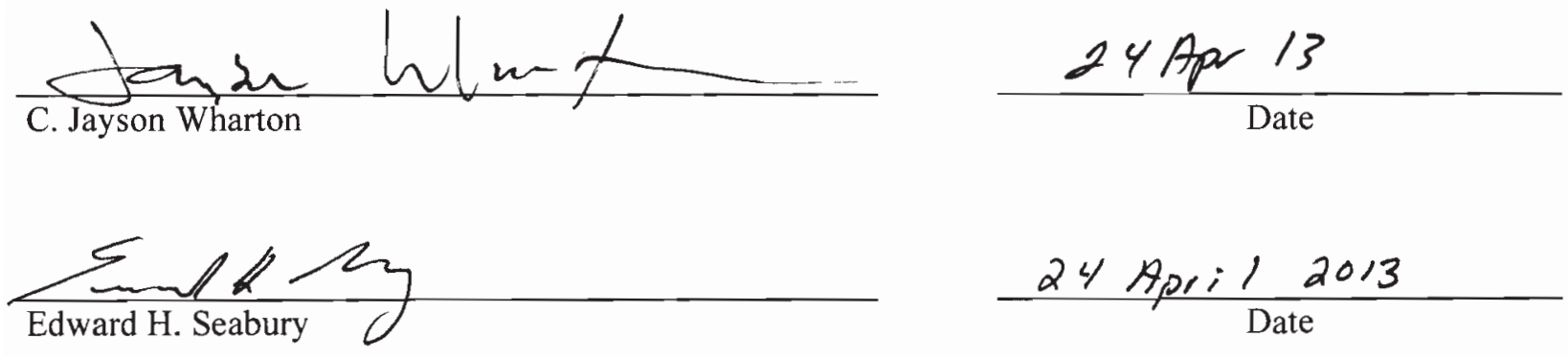

$\frac{24 \text { April } 2013}{\text { Date }}$
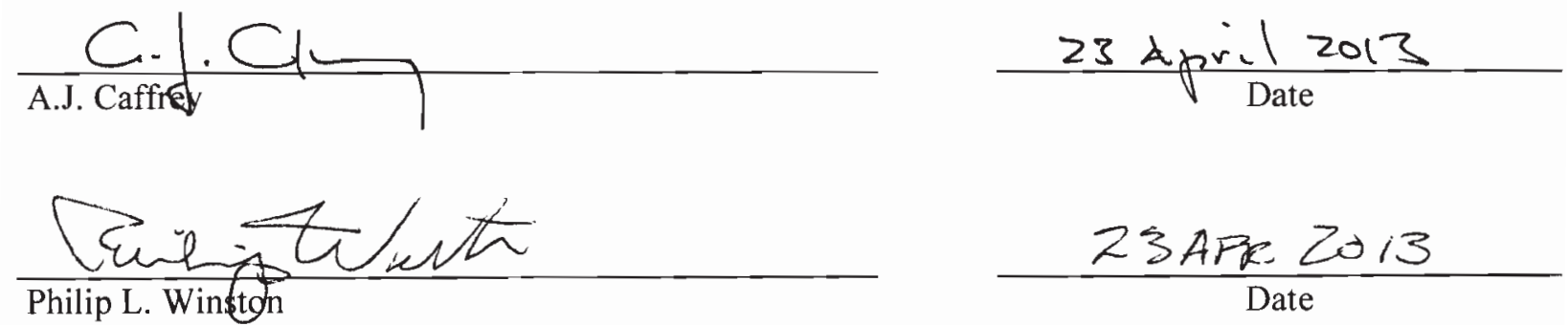



\section{SUMMARY}

In October and November 2012 the INL Compton Dry-Cask Imaging Scanner (CDCIS) was packaged and transported to the Doel Nuclear Power Plant near Antwerp, Belgium to perform a series of measurements on spent fuel storage casks. The task was performed in support of the DOE/NNSA NA-241 IAEA request 09/TAU-10 Restoration of CoK of LWR Fuel Assemblies by Gamma Scanning from the Top of Casks. The purpose of the measurements was to determine whether the system could by passive detection of the gamma rays being emitted by the contained spent fuel, confirm the presence or absence of the nuclear fuel bundles in a known, verified dry storage cask. If successful, the system, would be used to confirm the presence of the nuclear fuel bundles on four casks in storage that had lost continuity of knowledge due to problems verifying the status of the casks' Tamper Indicating Device (TID) seals.

Although proof of principle testing at INL on the Westinghouse MC-10 cask demonstrated the ability of the CDCIS to detect empty vs. full storage positions in the cask, and MCNP modeling indicated that the Doel casks should have sufficient decay energy to detect fission and activation product gamma ray peaks, the presence of a thick steel ballistic shield on the Belgian casks scattered the gamma energy to such an extent that discrete peaks were not able to be identified, truncating the test without being able to distinguish the empty-full status of the casks. 


\section{ACKNOWLEDGEMENTS}

The INL team acknowledges the support of Dr. Marc Humphrey of DOE/NA-241, and we greatly appreciates the assistance of Messrs. Matthias Burm, Rony Verdickt, and multiple Electrabel operations personnel at Doel Nuclear Power Station, Mr. Paul Anthonissen, and Ms. Katie DuPont of the Belgian Federaal Agentschap voor Nucleaire Controle, Messrs. Paul DeBaere, Martin Van Den Boomen, and Ali Zein of Euratom, and Ms. Monica Lavanderos-Alonso , Dr. Young-Gil Lee and Dr. Hong-Ryul Cha of IAEA. Dr. Jo Jae of Brookhaven National Laboratory provided interface assistance.

Nuclear reactor spent-fuel storage cask monitoring research at Idaho National Laboratory has been funded by the National Nuclear Security Administration (NNSA) Office of Dismantlement and Transparency and the NNSA Office of Nonproliferation Research and Development, under DOE Idaho Operations Office contract number DE-AC07-05ID14517. 


\section{CONTENTS}

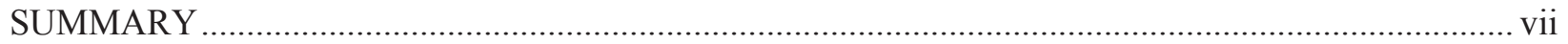

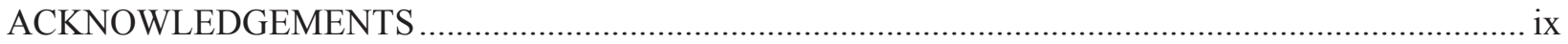

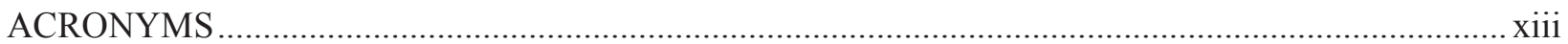

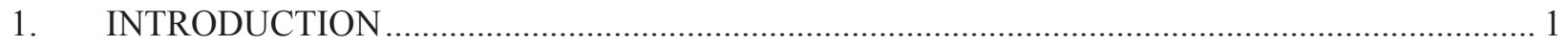

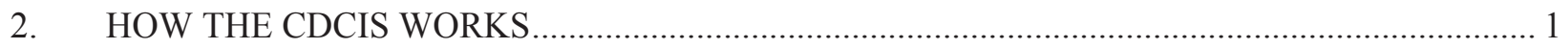

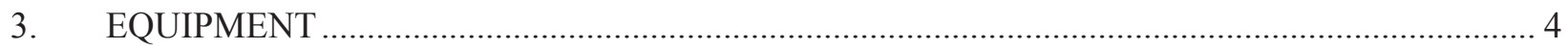

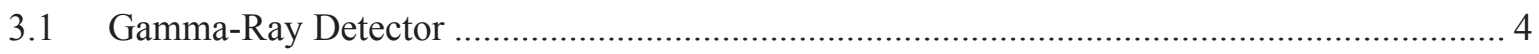

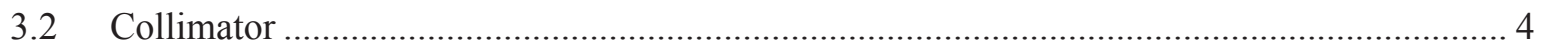

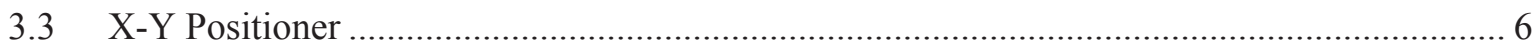

4. MEASUREMENTS AT THE DOEL NUCLEAR POWER FACILITY IN BELGIUM................... 6

4.1 MCNP Comparison of MC-10 and TN-24 Dry Spent Fuel Casks....................................... 7

4.2 Doel Nuclear Power Facility Measurements................................................................ 9

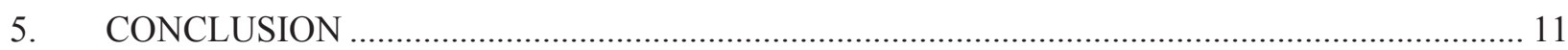

\section{FIGURES}

Figure 1. Schematic cross section of the Westinghouse MC-10 cask showing an empty fuel position. 1

Figure 2. The record of gamma rays detected during the REA 2023 cask testing in 2005. 2

Figure 3. A Monte Carlo simulation of Compton scattering events in a thin piece of steel. Note that only one in fifty gamma rays passes directly through the steel without scattering. 3

Figure 4. Comparison of gamma-ray spectra recorded over full (upper curve) spent-fuel slot and an empty (lower curve) cask slot.

Figure 5. A cutaway representation of the detector and collimator assembly, showing the limited

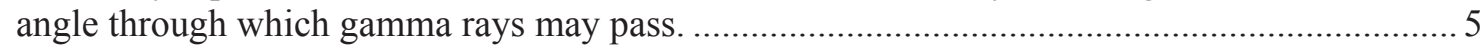

Figure 6. CDCIS installed on MC-10 Cask at INL during Proof-of Principle testing............................... 6

Figure 7. Conceptual cask scanner and shield nominal configuration.................................................... 7

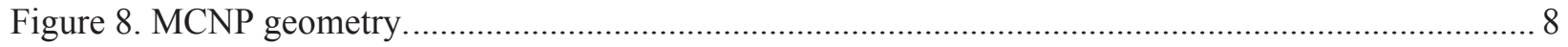

Figure 9. The CDCIS system system located on top of the empty model TN-24-DH spent fuel cask as viewed from the side and from above. 10

Figure 10. Comparison of the 15-hour sum spectra and the 1-hour spectrum taken from the side of the cask. The spectral lines from the fission product dominate the side scan but are not present in the spectra from above, even after 15 hours. 


\section{TABLES}

Table 1. High Purity Germanium detector details. .................................................................................. 4

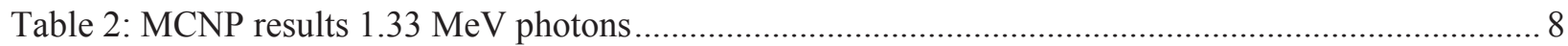

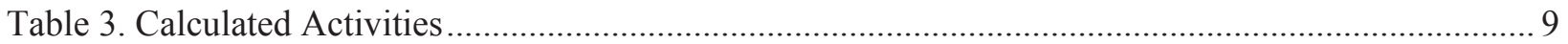




\section{ACRONYMS}

$\begin{array}{ll}\text { CDCIS } & \text { Compton Dry-Cask Imaging Scanner } \\ \text { CoK } & \text { Continuity of Knowledge } \\ \text { DOE } & \text { U.S. Department of Energy } \\ \text { HPGe } & \text { High Purity Germanium } \\ \text { IAEA } & \text { International Atomic Energy Agency } \\ \text { INL } & \text { Idaho National Laboratory } \\ \text { INTEC } & \text { Idaho Nuclear Technology and Engineering Center } \\ \text { keV } & \text { Kilo-electron-volt } \\ \text { LWR } & \text { Light Water Reactor } \\ \text { MCNP } & \text { Monte Carlo N-Particle } \\ \text { MeV } & \text { Mega-electron-volt } \\ \text { NNSA } & \text { National Nuclear Security Administration } \\ \text { PWR } & \text { Pressurized Water Reactor } \\ \text { TID } & \text { Tamper Indicating Device }\end{array}$




\section{INL CDCIS CASK SCANNER TESTING AT DOEL, BELGIUM}

\section{INTRODUCTION}

In October and November 2012 the INL Compton Dry-Cask Imaging Scanner (CDCIS) was packaged and transported to the Doel Nuclear Power Plant near Antwerp, Belgium to perform a series of measurements on spent fuel storage casks. The task was performed in support of the DOE/NNSA NA-241 IAEA request "09/TAU-10 Restoration of CoK of LWR Fuel Assemblies by Gamma Scanning from the Top of Casks". The purpose of the measurements was to determine whether the system could by passive detection of the gamma rays being emitted by the contained spent fuel, confirm the presence or absence of the nuclear fuel bundles in a known, verified dry storage cask. If successful, the system would be used to confirm the presence of the nuclear fuel bundles on four casks in storage that had lost continuity of knowledge due to problems verifying the status of the casks' tamper indicating device (TID) seals.

The CDCIS uses a gamma-ray spectrometer to detect specific isotopes and associated Compton scattered energy to produce a map of the spent-fuel assemblies in a dry-storage cask, allowing inventory of spent-fuel assemblies without the need to open the cask. The mapping is performed from the top of the cask to be able to have a clear view of each fuel assembly inside the cask internal structure.

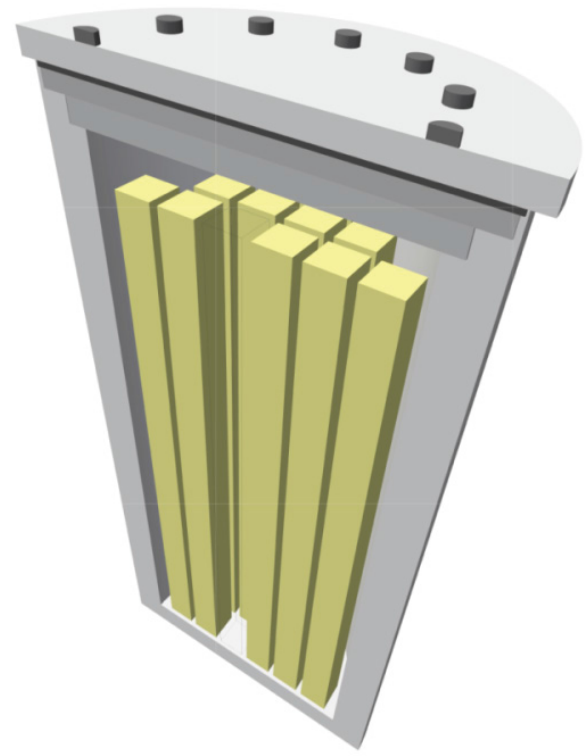

Figure 1. Schematic cross section of the Westinghouse MC-10 cask showing an empty fuel position.

Following use in power production, nuclear fuel assemblies contain radioactive isotopes that result from nuclear fission of uranium. These isotopes emit high-energy gamma ray photons that are a health hazard that is mitigated by the use of massive material such as steel or concrete shielding to absorb the energy. The CDCIS imager detects the gamma rays that escape the cask shielding with sufficient spatial resolution to determine whether a fuel bundle is present or absent in each individual cask slot. The detector's high energy resolution allows it to confirm the determination by detecting gamma rays produced by several activation- and fission-product isotopes.

\section{HOW THE CDCIS WORKS}

Gamma rays are photons that are emitted from the nuclei of radioisotopes. Gamma-ray spectroscopy identifies the presence and quantity of specific isotopes by measuring gamma-ray energies. Radioisotopes 
emit gamma rays that have energies that are specific to each isotope. Cobalt- 60 and cesium- 137 emit gamma rays that are sufficiently energetic to be detected through the shield walls of the storage cask. Co-60 is present from neutron activation of stainless steel components of the fuel bundle, and Cs-137 is a dominant fission product in uranium fuel. Testing of the CDCIS at the Idaho National Laboratory confirmed that it is possible to distinguish empty storage positions in the cask from ones that contain fuel bundles.

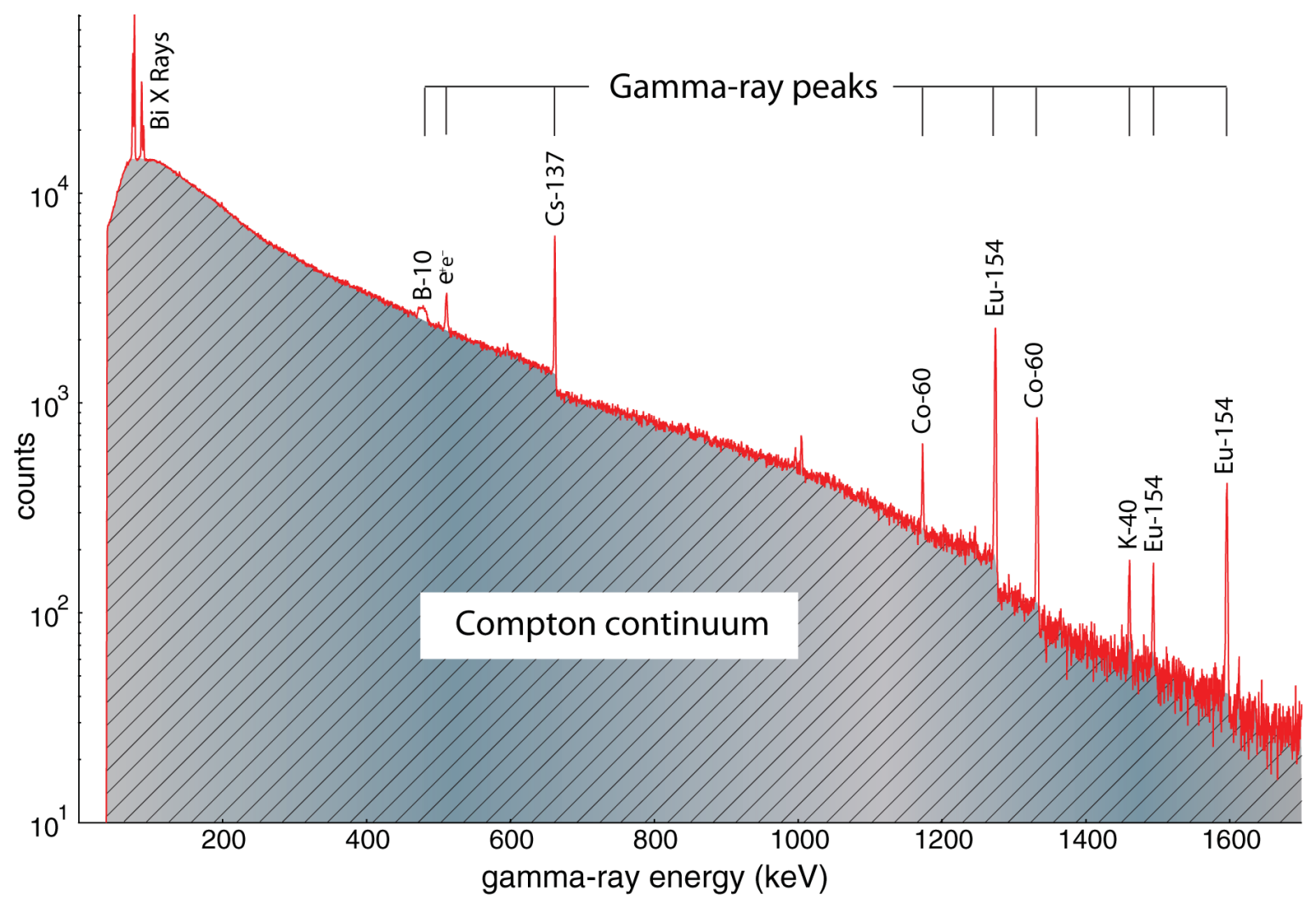

Figure 2. The record of gamma rays detected during the REA 2023 cask testing in 2005.

The gamma-ray-emitting radionuclides are identified by the energies of the peaks in the measured energy spectrum. Cobalt-60 produces gamma rays at 1173 and 1332 kiloelectron volts (keV) as seen in the spectrum displayed in Figure 2. The net areas of these peaks are directly proportional to the source strength.

The plateaus between the sharp peaks in Figure 2 are known as Compton continua. The counts in these spectral regions are produced by gamma rays that have been scattered and lost varying fractions of their original energy due to interaction with the electron clouds of other atoms, known as the Compton effect.

The gamma-ray energy reduction depends on the Compton scattering angle. A 1,000 keV gamma ray loses $80 \%$ of its energy if it Compton scatters backwards, 180 degrees from its initial direction. Even if a gamma ray scatters by as little as 3-4 degrees, its energy loss is sufficiently great that it will no longer appear in a peak when measured with a high-resolution detector. Rather, it is appears in the spectrum as a count at a lower energy, in the flat Compton continua between the gamma-ray peaks shown in Figure 2. Hence, energy spectroscopy can distinguish between Compton-scattered and unscattered gamma rays: the scattered gamma rays are recorded in the spectral Compton continuum while the unscattered gamma rays register in the spectral peaks.

The shielding of spent-fuel casks causes most gamma rays to lose energy by multiple 
Compton scattering events until all of its energy is absorbed in the shielding material. Figure 5 shows a Monte Carlo model of gamma-ray scattering in a thin piece of steel. More detailed Monte Carlo calculations show that about one spent-fuel gamma ray in one hundred thousand penetrates the cask shielding, and of those gamma rays, one in three hundred emerges unscattered, that is, with its initial energy and direction.

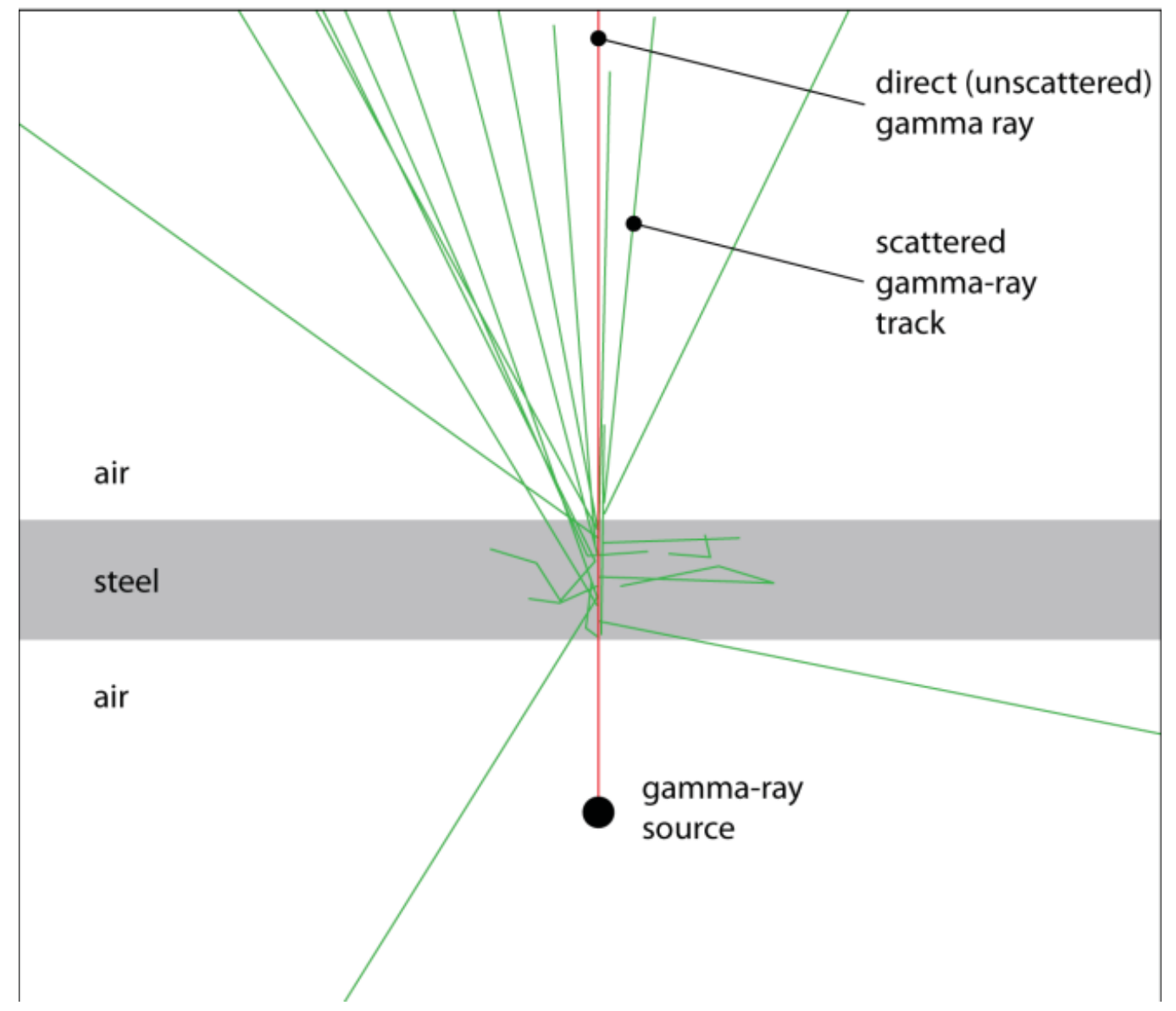

Figure 3. A Monte Carlo simulation of Compton scattering events in a thin piece of steel. Note that only one in fifty gamma rays passes directly through the steel without scattering.

When a gamma-ray detector is placed directly above a filled spent-fuel slot, unscattered gamma radiation reaches the detector, and registers as counts in spectral peaks. When the detector is moved to a position above an empty slot, most of the radiation that reaches the detector has Compton scattered, and the energies of these gamma rays are therefore too low to register in a peak. Instead, they appear in the Compton continuum. It is not possible to screen the gamma-ray detector from every unwanted gamma ray. Some scattered radiation reaches the detector despite its being positioned above a full slot. Likewise, some direct radiation hits the detector when it is located above an empty slot. However, the ratio of peak to Compton-continuum counts is high above full slots and conversely, the ratio is low above empty slots, as shown in Figure 4. 


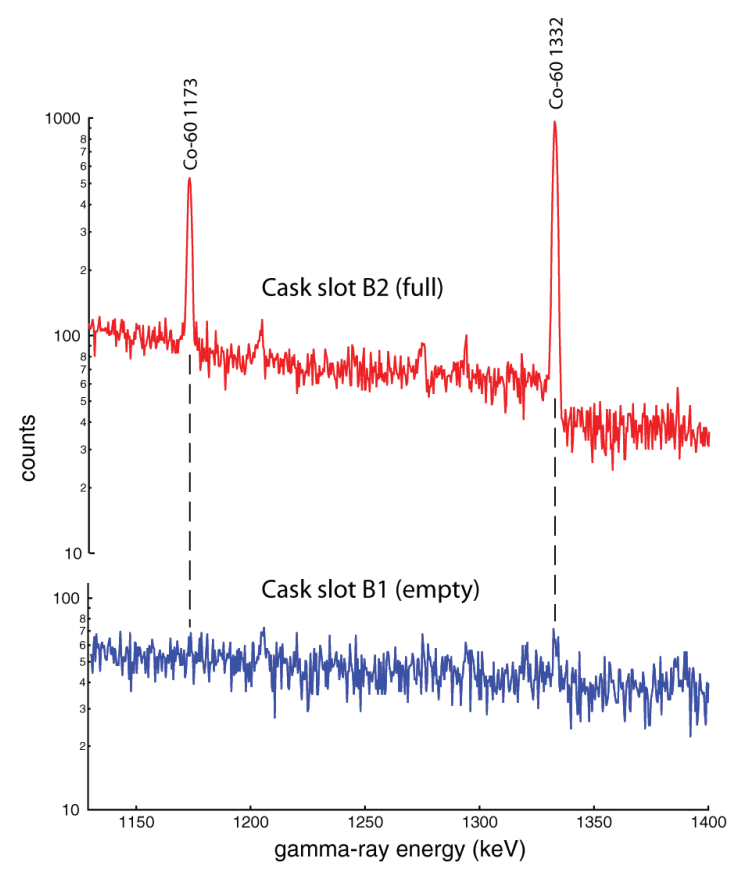

Figure 4. Comparison of gamma-ray spectra recorded over full (upper curve) spent-fuel slot and an empty (lower curve) slot, inside a Westinghouse MC-10 spent-fuel cask at Idaho National Laboratory.

\section{EQUIPMENT}

The principal scanner components are the gamma-ray detector, the gamma-ray collimator, and the $x-y$ positioner.

\subsection{Gamma-Ray Detector}

The heart of the cask imager is a high-purity germanium (HPGe) gamma-ray detector. This instrument measures gamma energies to an uncertainty of one part in a thousand for the important fission-product gamma rays. The detector's excellent energy resolution permits a rapid analysis of the spectral data to determine slot peak-to-Compton ratios.

Two $n$-type HPGe detectors were used to collect the experimental data taken at the Doel Nuclear Power facility. The specifics for each detector are given in Table 1 below.

Table 1. High Purity Germanium detector details.

\begin{tabular}{|l|c|c|c|c|c|}
\hline PINS Detector & Ortec Model No. & $\begin{array}{c}\text { Crystal } \\
\text { Diameter } \\
(\mathrm{mm})\end{array}$ & $\begin{array}{c}\text { Crystal } \\
\text { Length } \\
(\mathrm{mm})\end{array}$ & $\begin{array}{c}\text { Measured } \\
\text { Resolution } \\
\text { at } 1.33 \mathrm{MeV}\end{array}$ & $\begin{array}{c}\text { Measured Relative } \\
\text { Efficiency } \\
\text { at } 1.33 \mathrm{MeV}\end{array}$ \\
\hline P30 & GMX-40195-P-S & 67.3 & 65.2 & $1.90 \mathrm{keV}$ & $47.0 \%$ \\
\hline P70 & GMX-40195-P-S & 69.4 & 62.6 & $1.92 \mathrm{keV}$ & $44.8 \%$ \\
\hline
\end{tabular}

\subsection{Collimator}

It is critical that the cask scanner's detector views only the spent-fuel slot directly below it. Otherwise, gamma-rays from adjacent slots, especially full slots, could alter the peak-to-Compton ratio of the slot being measured. The detector is shielded from off-axis gamma rays by a collimator fabricated from 500 pounds $(226 \mathrm{~kg})$ of tungsten. The collimated detector's view of the spent fuel is shown in Figure 7. 

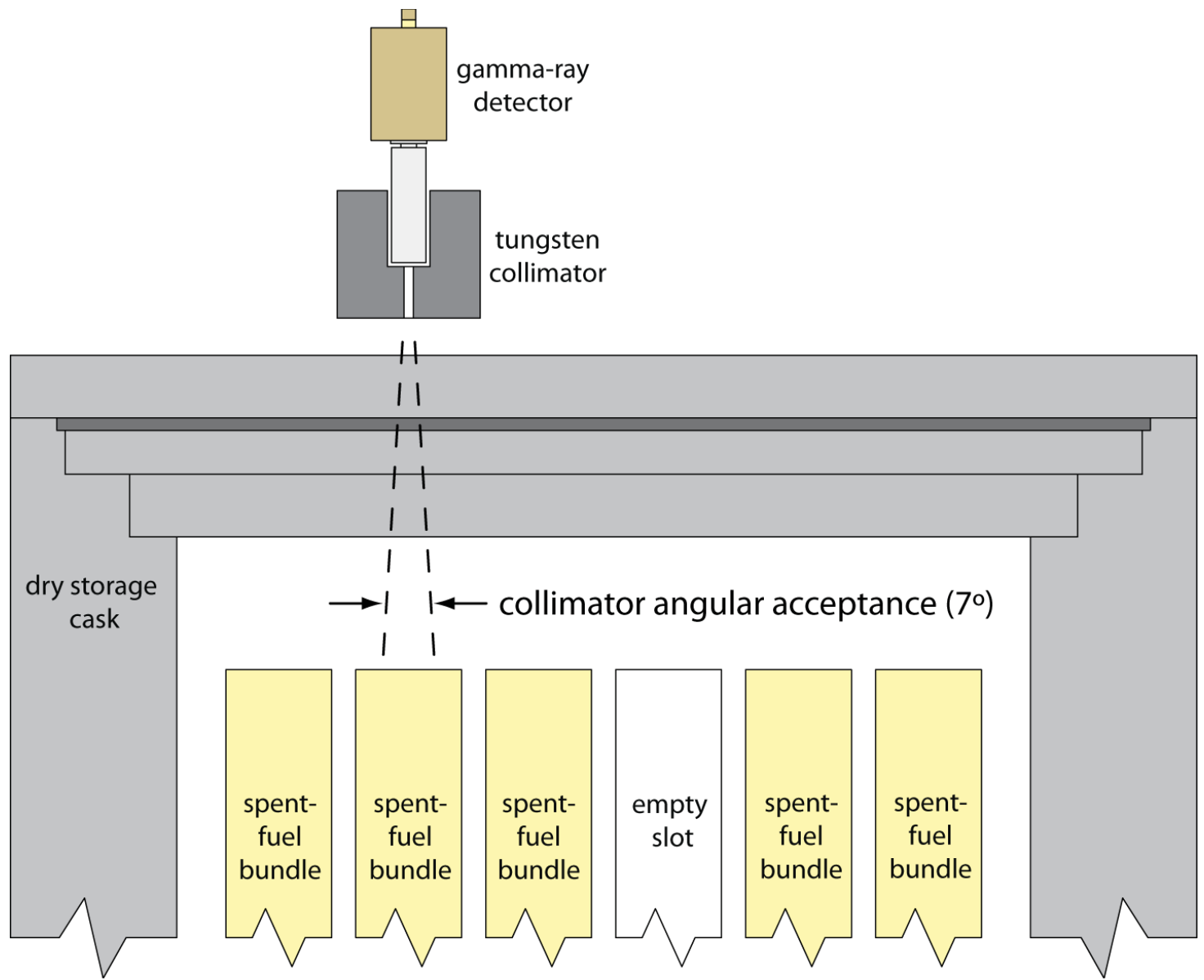

Figure 5. A cutaway representation of the detector and collimator assembly, showing the limited angle through which gamma rays may pass. 


\subsection{X-Y Positioner}

The $\mathrm{x}-\mathrm{y}$ positioner moves the collimated detector from slot to slot above the cask, locating the detector centerline within 0.25 -inch of each slot center. The positioner can move the 500-pound collimator and detector to any slot in about 10 seconds. A notebook computer controls the motion of the $\mathrm{x}-\mathrm{y}$ positioner, operates the gamma-ray spectrometer, analyzes the gamma-ray spectra, and calculates the peak-to-Compton ratios for the cask map.

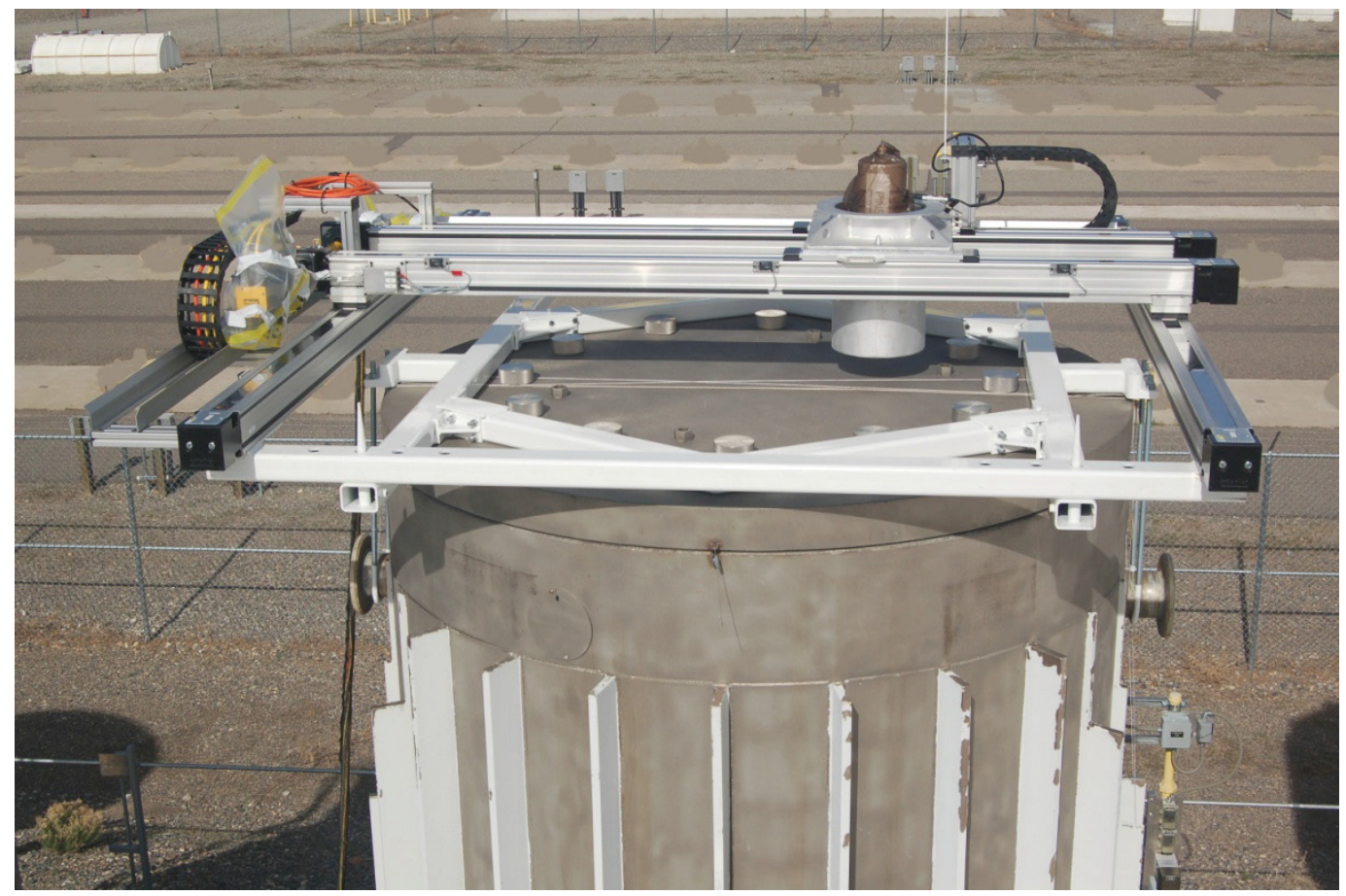

Figure 6. CDCIS installed on MC-10 Cask at INL during Proof-of Principle testing.

\section{MEASUREMENTS AT THE DOEL NUCLEAR POWER FACILITY IN BELGIUM}

The measurements at the Doel facility were planned to occur in two phases. Phase I consisted of the assembly of the system, verification of system functionality, and a series of measurements on an empty spent fuel cask located in the mock-up area of the fuel storage facility. Once the system was deemed functional, the system would be removed from the cask to allow the facility to then fill the cask with spent nuclear fuel in preparation for Phase II. Phase II would consist of placing the CDCIS system on top of the now-full spent fuel cask and repeating the Phase I measurements, comparing the results to confirm the detection of the spent fuel bundles in each fuel slot. If the system could confirm the presence of each fuel bundle, the system would then be moved into the facility storage area and used to verify the radiation signatures for each of the fuel bundles in the four spent fuel casks that had lost TID integrity.

The casks to be measured are TransNuclear (Areva) TN-24 designs, models 24D, DH, XL or XLH, containing either 24 or 28 fuel bundles from Pressurized Water Reactors (PWR). These casks have a primary carbon steel shield wall that is 9 inches $(23 \mathrm{~cm})$ thick. 
At the Doel Nuclear Power facility, a 18-cm (7.1-inch) thick ballistic shield is placed onto the top of each spent fuel cask to protect it in the case of an airplane impact. This carbon-steel shield, while protecting the cask, also blocks many of the gamma rays being emitted by the spent nuclear fuel inside, the very signature needed by the CDCIS system to verify the cask contents. As the CDCIS system had never been tested on a cask with a ballistic shield in place, Monte Carlo (MCNP) neutron models were performed to determine the fraction of gamma radiation that would pass through the shield.

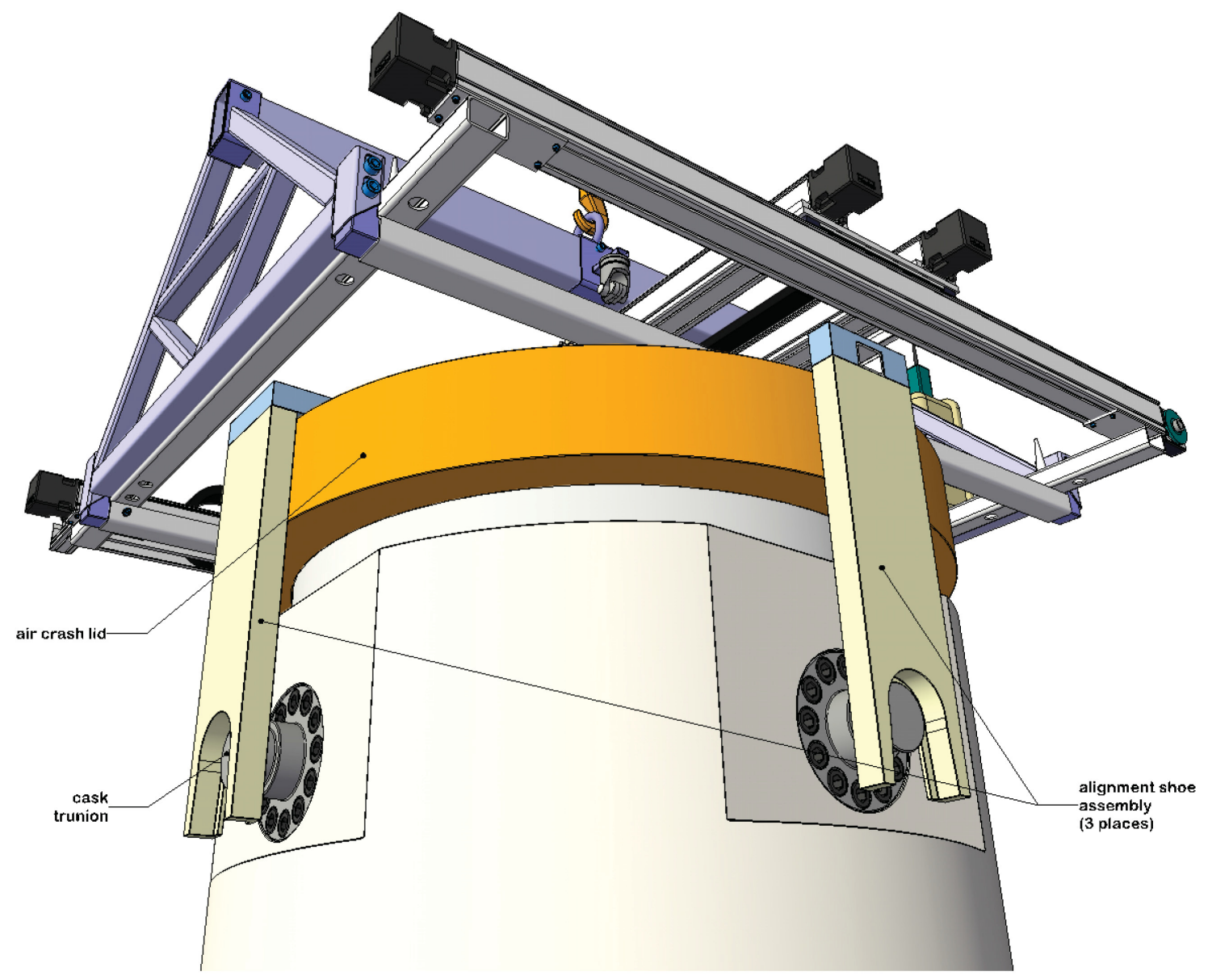

Figure 7. Conceptual cask scanner and shield nominal configuration.

\subsection{MCNP Comparison of MC-10 and TN-24 Dry Spent Fuel Casks}

The CDCIS system has been tested on a Westinghouse MC-10 storage cask at the Idaho Nuclear Technology and Engineering Center (INTEC). Because the TN-24 casks have additional steel shielding that could interfere with the successful use of the CDCIS, MCNP calculations were performed examining the gamma-ray attenuation of the shields on both the MC-10 and TN-24 casks so that previous measurements at INTEC could be compared with expected results from TN-24 measurements.

A model of the MC-10 cask had been made for earlier development of the CDCIS. This model included fuel bundles, the cask lid, and the HPGe detector. A screen shot of the geometry is shown in Figure 8 below. The HPGe crystal and the shielding around the detector are at the top of the figure. 


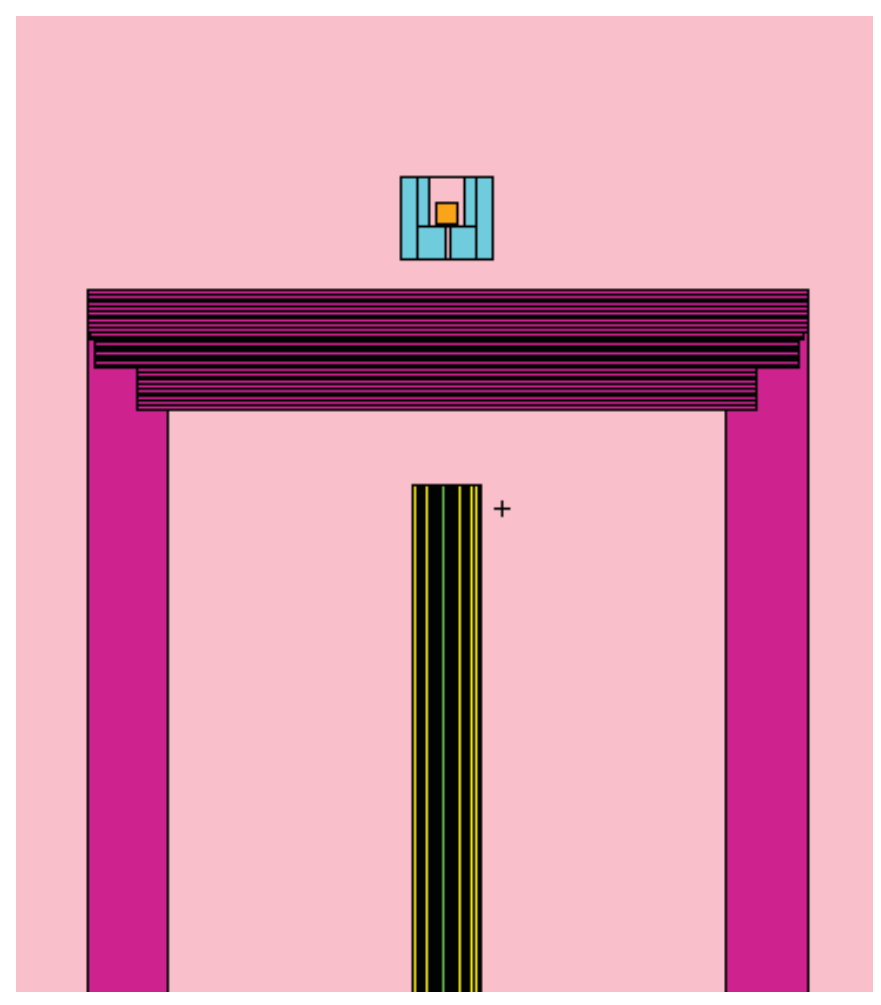

Figure 8. MCNP geometry.

The steel lid of the MC-10 cask has a total thickness of $36.8 \mathrm{~cm}$ (14.5 inches) steel. The TN-24 cask with its lid and ballistic shield has a total of $45 \mathrm{~cm}$ (17.7 inches) of steel. This difference in thickness has a significant effect on the attenuation of gamma rays through the cask. For the comparison of the two different casks the model included a $1.33-\mathrm{MeV}(1332 \mathrm{keV})$ photon source placed in the location of the fuel elements. The detector location was held constant for the calculations, with the difference between the two geometries consisting solely of the thickness of the steel lids. No air gaps or neutron shielding materials were included in the MCNP calculations.

The models tallied energy deposition in the HPGe crystal, a detector tally of the HPGe crystal volume, a photon flux tally on the surface of the HPGe crystal closest to the top of the cask, and a point detector tally of photon fluence placed $1 \mathrm{~cm}$ within the HPGe detector volume. A summary of the results can be seen in Table 2 below. As can be seen in the table, the additional steel reduces the peak intensity by a factor of approximately 26.5 when comparing the TN-24 with the MC10.

Table 2: MCNP results for $1.33 \mathrm{MeV}(1332 \mathrm{keV})$ photons

\begin{tabular}{|l|c|c|c|c|c|c|c|c|}
\hline & $\begin{array}{c}\text { Flux } \\
\left(\mathrm{p} / \mathrm{cm}^{2}\right) \\
\text { Peak }\end{array}$ & $\begin{array}{c}\text { Flux } \\
\left(\mathrm{p} / \mathrm{cm}^{2}\right) \\
\text { Total }\end{array}$ & $\begin{array}{c}\text { Energy } \\
\text { deposition } \\
\text { MeV/cm } \\
\text { Peak }\end{array}$ & $\begin{array}{c}\text { Energy } \\
\text { deposition } \\
\text { MeV/cm } \\
\text { Total }\end{array}$ & $\begin{array}{c}\text { Point } \\
\text { Detector } \\
\left(\mathrm{p} / \mathrm{cm}^{2}\right) \\
\text { Peak }\end{array}$ & $\begin{array}{c}\text { Point } \\
\text { Detector } \\
\left(\mathrm{p} / \mathrm{cm}^{2}\right) \\
\text { Total }\end{array}$ & $\begin{array}{c}\text { Pulse } \\
\text { Height } \\
(\text { counts }) \\
\text { Peak }\end{array}$ & $\begin{array}{c}\text { Pulse } \\
\text { Height } \\
(\text { counts }) \\
\text { Total }\end{array}$ \\
\hline TN-24 & $2.68 \mathrm{E}-13$ & $1.25 \mathrm{E}-12$ & $4.42 \mathrm{E}-15$ & $3.22 \mathrm{E}-14$ & $1.26 \mathrm{E}-13$ & $3.77 \mathrm{E}-13$ & $7.58 \mathrm{E}-14$ & $1.25 \mathrm{E}-12$ \\
\hline $\mathrm{MC} 10$ & $7.10 \mathrm{E}-12$ & $3.04 \mathrm{E}-11$ & $1.17 \mathrm{E}-13$ & $7.84 \mathrm{E}-13$ & $3.46 \mathrm{E}-12$ & $9.66 \mathrm{E}-12$ & $2.01 \mathrm{E}-12$ & $3.07 \mathrm{E}-11$ \\
\hline Ratio & 26.54 & & 26.52 & & 27.41 & & 26.48 & \\
\hline
\end{tabular}

To compare the results of measurements at INTEC with anticipated results from the Belgian casks, the differing ages of the fuels stored in each cask was also taken into account. 
The gamma ray spectrum measured with the CDCIS detector positioned over a specific slot, A1, measured a total of 9228 counts in the $1.33-\mathrm{MeV}$ Co-60 gamma ray photopeak in 1,000 seconds. The fuel in this slot was removed from the reactor in June 1981. The fuel in the TN-24 casks at Doel was removed from its reactor in 2003. If we assume that the fuel bundles in each of these casks held the same amount of Co-60 at the time of their removal, then we can correct for the decay of the Co-60 and compare the anticipated count rates between the MC-10 and TN-24 casks.

Table 3 below shows the calculated relative Co-60 activity for the INTEC MC-10 and Doel TN-24 casks, assuming an initial activity of $100 \mathrm{Ci}$ for simplicity.

Table 3. Calculated Activities

\begin{tabular}{|l|c|l|l|c|}
\hline & $\begin{array}{c}\text { Original Activity } \\
(\mathrm{Ci})\end{array}$ & Date of Removal & \multicolumn{1}{|c|}{ Date of Measurement } & $\begin{array}{c}\text { Activity on Date } \\
\text { of Measurement } \\
(\mathrm{Ci})\end{array}$ \\
\hline MC-10 & $100 \mathrm{Ci}$ & June 1981 & 14 May 2008 & 3.06 \\
\hline TN-24 & $100 \mathrm{Ci}$ & November 2003 & 01 September 2012 & 30.06 \\
\hline
\end{tabular}

The MCNP calculations described showed that the expected 1.33-MeV gamma count rate of the Doel casks would be reduced by a factor of approximately 26.5 in comparison the INTEC MC-10 cask due to the increased steel shielding. The Co-60 activity calculations show that the Doel fuel should have approximately 10 times the Co-60 that the INTEC MC-10 fuel had when gamma spectra were measured. This leads to the conclusion of an expected $1.33 \mathrm{MeV}$ gamma count rate of $10 / 26.5$ or $38 \%$ that of the INTEC MC-10 fuel for the Doel fuel.

Given that a slot on the MC-10 cask yielded approximately 9000 counts in the Co-60 $1.33 \mathrm{MeV}$ peak in 1000 seconds, one could anticipate detecting 3420 counts in 1000 seconds from the Doel fuel. This corresponds to a peak area statistical uncertainty of $1.7 \%$.

\subsection{Doel Nuclear Power Facility Measurements}

In October 2012 the CDCIS system was shipped to the Doel Nuclear Power facility near Antwerp, Belguim. Two INL scientists assembled the system and verified its functionality. On 10-11 October 2012, the system was assembled and lifted via overhead crane onto an empty model TN-24-DH spent fuel cask located in the mockup area of the fuel storage facility. The system functioned normally and data was taken above several spent fuel bundle locations to verify there was no radiation signature from the empty cask. When, the system functions had been confirmed, it was removed from the top of the cask and moved to a storage location. Figure 9 shows the system on the empty cask. 

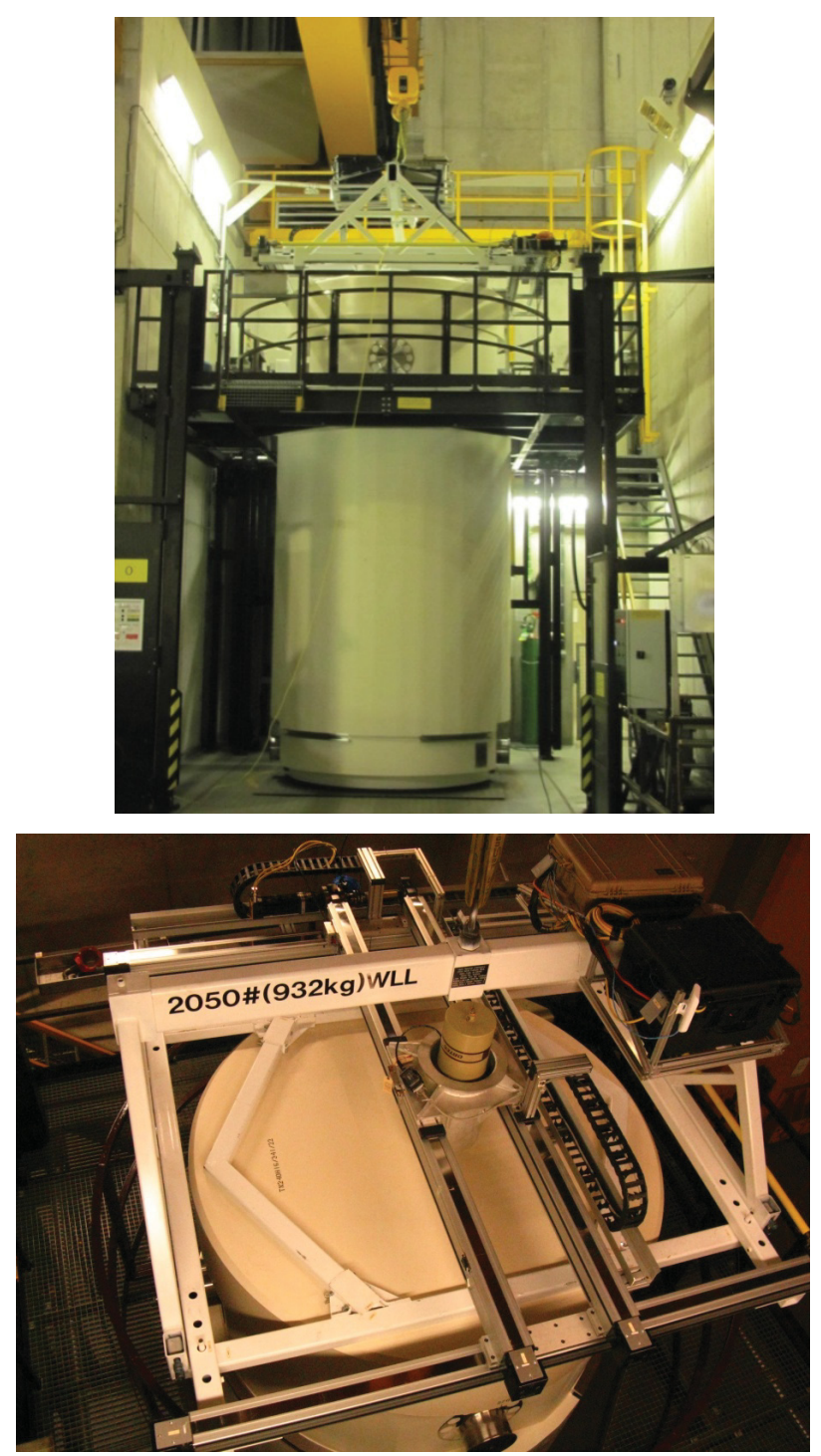

Figure 9. The CDCIS system system located on top of the empty model TN-24-DH spent fuel cask as viewed from the side and from above.

Phase II testing began in November. Due to other activities at the spent fuel storage facility, only two days were allowed for verification of the full cask.

On November 12, 2012, the CDCIS system was positioned on the now-full TN-24-DH cask and set up to count overnight. The X-Y positioner of the CDCIS was programmed to move to a selected fuel bundle location, dwell there until 3,000 live second counts were acquired by the HPGe detector then move to the next bundle location, continuing until all 28 fuel bundle locations had been counted. In addition, one "background" location, near the edge of the cask away from any fuel bundles was also be measured for 3,000 live seconds.

On the following morning, it was found that the system had completed counting 18 of the 28 bundle locations as well as the background location. When examined, the spectra did not show any of the photopeaks indicative of the presence of spent fuel, so the remainder of the automated scan cycle was aborted. 
Normally, the CDCIS sytem is operated with a $1.27-\mathrm{cm}$ (0.5-inch) aperture collimator to improve spatial resolution. Because no discrete Co- 60 or Cs- 137 photopeaks were evident in the data collected the previous night, this smaller collimator was replaced with one having a $2.54-\mathrm{cm}$ (1-inch) aperature, theoretically increasing the count rate by a factor of four. When no discrete peaks at 662,1173 or $1332 \mathrm{keV}$ were seen, this larger collimator was removed as well, leaving the full 8.9-cm (3.5-inch) aperture that corresponds to the outside diameter of the detector cap. Tests with the full aperture also showed no discrete peaks. One final measurement was taken with the detector completely removed from the tungsten housing and placed directly on top of the ballistic shielding. Even in this configuration on top of the cask, directly over a spent fuel bundle, no Co, Cs, and Eu gamma rays could be identified.

During these measurements, the system dead time, the percentage of time the detector is busy processing counts, was less then 3\% with the smallest collimator and was never greater than $10 \%$ even with the largest aperture. Even when the detector was completely removed from its tungsten housing and placed directly on top of the cask, the system dead time was only measured to be $30 \%$.

It was decided to assay the cask from the side instead of the top to verify the gamma rays of interest could be detected where there was no ballistic shield. When data was taken from the side of the cask, it was necessary to move the HPGe detector to a distance of 5 meters ( 16 feet) from the cask wall to be able to reach acceptable dead time levels (below 40\%). At 5 meters, the 1173 and 1332-keV Co-60 peaks were both present in the spectra as were the 1274 and $1005 \mathrm{keV}$ Eu-154 peaks, the 796, 1039, 1173, and $1365 \mathrm{keV}$ Cs-134 peaks and the 662-keV Cs-137 peak.

As the system was unable to detect any $\mathrm{Co}, \mathrm{Cs}$, or Eu gamma rays from a spent fuel bundle through the ballistic shield, the additional measurements on the four casks in the storage area of the facility were not performed.

\section{CONCLUSION}

Despite MCNP predictions that indicated otherwise, the INL CDCIS system was unable to detect fission-product or activation gamma rays through the ballistic shield on top of the TN-24 cask. During the overnight automated runs, data was collected for 3,000 seconds on 18 full fuel bundles. To determine whether a longer count time could yield a spectrum where the photopeaks from any fission product could be seen, the data collected from all 18 fuel bundles were added together. The result would theoretically be similar to that of counting one bundle for 15 hours, the results are shown in Figure 10 below. In this "15-hour" spectum, the Co-60, Cs-134, \& Cs-137 peaks are still not present.

The gamma ray photopeaks seen in the recorded spectra could be attributed to either neutron interactions in the tungsten shielding or the germanium crystal of the detector. 


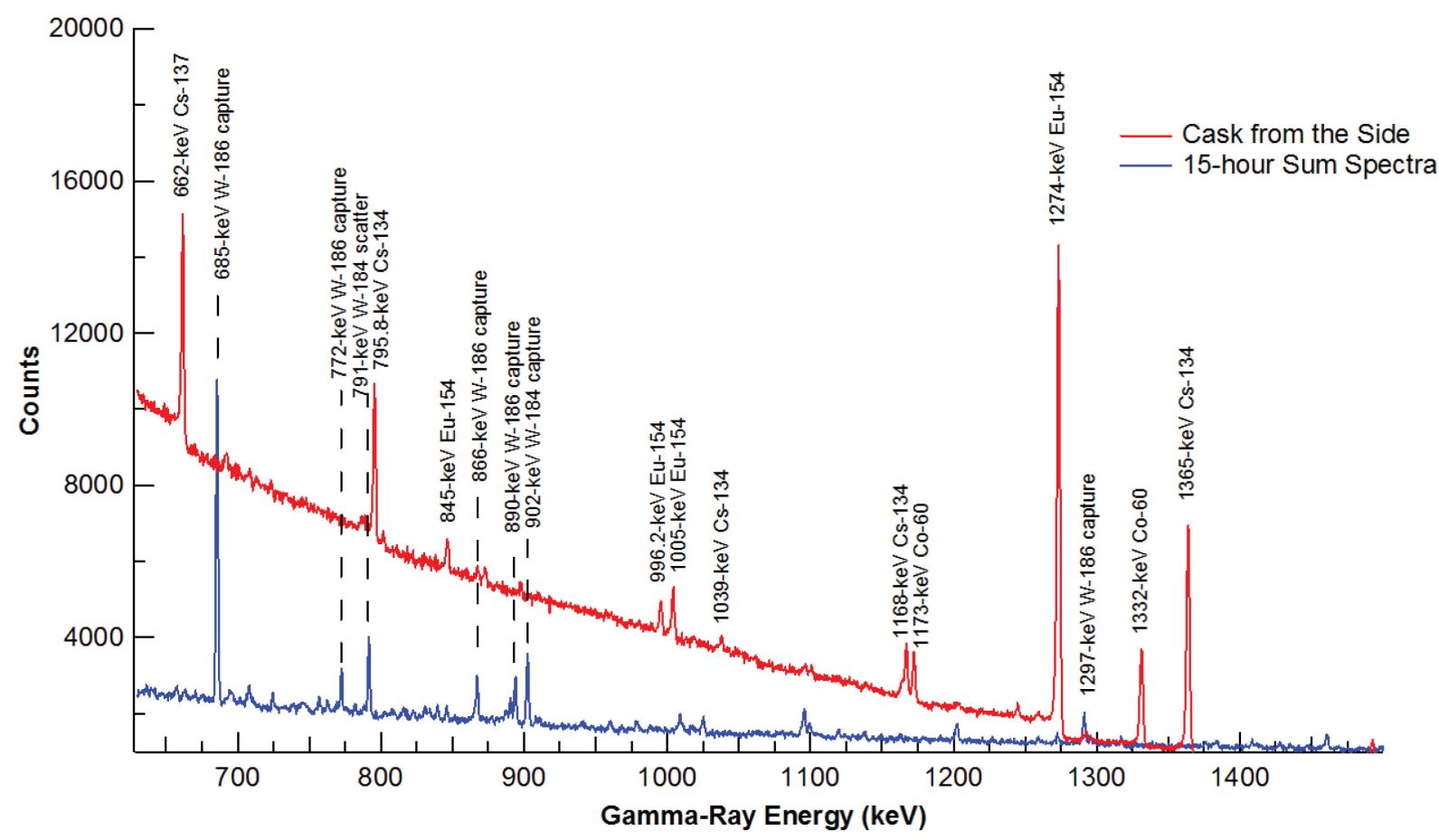

Figure 10. Comparison of the 15-hour sum spectra and the 1-hour spectrum taken from the side of the cask. The spectral lines from the fission product dominate the side scan but are not present in the spectra from above, even after 15 hours.

It appears that our Monte Carlo estimate overstated the gamma-ray intensity at our detector by an order of magnitude or more. There are two possible explanations for this deviation between the Monte Carlo model and the measured results. The first is the relative strength of the fission product and activation sources in the two casks was estimated incorrectly. The burnup of the fuel examined in the MC10 and used to determine the expected relative intensities in the Doel cask was $30.56 \mathrm{MWd} / \mathrm{MTHM}$. The only information regarding the fuel burnup provided by the utility was the net cask thermal load.

Our estimate of data collection times was based on assuming that the MC10 cask and the TN24 cask fuel bundles had identical fission and activation product inventories at the time they left their respective reactors. We believe this assumption is conservative, as the modern commercial power reactor trend is to obtain higher fuel burnup than was the practice in the 1980s. Further, the expected fission-product and activation product gamma-rays were observed through the side of the TN24 cask, traversing perhaps 8 -10 inches $(20-25 \mathrm{~cm})$ of steel.

A difference in our estimated inventory of the Doel spent fuel and the true inventory could play some role in the difference between the measured and predicted results, but the gamma-ray intensities at our detector scale linearly with the true burnup.

More likely, the Monte Carlo models were inaccurate in their respective geometries. While INL has significant MC10 cask documentation including detailed engineering drawings, we do not have a drawing of the TN24 cask, despite requests to both the utility and the cask manufacturer Areva. Since gamma-ray attentuation is an exponential function of attenuator thickness, a relatively modest change in shielding dimensions can cause a large change gamma-ray attenuation. If the top of the cask has two inches $(5 \mathrm{~cm})$ more steel than we estimated, that would be sufficient to reduce the gamma-ray intensity at the detector by an order of magnitude. 
INL plans on performing additional measurements and calculations in order to fully understand the source of the deviation between Monte Carlo-based prediction of the CDCIS response and measurements of the Doel cask. This would also allow us to predict whether future measurements on other casks with varying shielding configurations and fuel inventories are practical in a timely fashion. 